\title{
Los límites del sujeto y la libertad en Ortega y Gasset
}

\author{
The limits of individual and liberty in Ortega y Gasset
}

\author{
RODOLFO GUTIÉRREZ SIMÓN*
}

\begin{abstract}
Resumen: Partiendo de la crítica a la "ética de la vocación" de Ortega y Gasset se procederá a explicitar sus supuestos y sus consecuencias, mostrando cómo supone una quiebra en la individualidad del sujeto. A partir de ahí, se mostrará el concepto de libertad que tales posiciones implican.
\end{abstract}

Palabras clave: Ortega, ética, política, libertad, vocación, individuo.

\begin{abstract}
From the critics of the "ethic of calling" by Ortega y Gasset, its assumptions and consecuences will be explicited, highliting fails in the individual. Later we will show the liberty conception implied in that position.

Keywords: Ortega, ethics, polithics, liberty, calling, individual.
\end{abstract}

\section{Hipótesis de partida: el hombre-masa como concepto fundamental}

Antes de comenzar con la crítica de la ética de la vocación y de la libertad que de ella se desprende, es preciso que explicitemos una idea que se encuentra en la base de nuestra argumentación. Dicha ética nace como respuesta a distintos factores. Por una parte, está enfrentada a la moral utilitarista y a la deontológica; por otra, arranca desde una crítica hacia una forma de vida individual y política imperante en su momento -y que, por tanto, es también su circunstancia. Así, señala en Kant: «Hoy, [...], nos sorprende hallar que en el hombre de aspecto más tranquilo truena una remota tormenta abisal, una congoja profunda. La forma

Fecha de recepción: 03/02/2015. Fecha de aceptación: 24/05/2015.

* Doctorando en la Universidad Complutense de Madrid (España), Facultad de Filosofía, bajo la dirección de José Luis Villacañas Berlanga y Antonio Rivera García, con la tesis Ortega y el pragmatismo norteamericano. Influencias y confluencias. Correo electrónico: rodolfo.gutierrez@ucm.es. Contrato predoctoral de personal investigador en formación de la Universidad Complutense de Madrid (Departamento de Historia de la Filosofía, Estética y Teoría del Conocimiento). Miembro del Consejo de Redacción de la Revista Hispanismo Filosófico, componente activo del Grupo de Investigación en Pensamiento Español y Latinoamericano de la UCM y colaborador de la Biblioteca Saavedra Fajardo de Pensamiento Político Hispánico. Líneas de investigación: la filosofía de Ortega y Gasset y el pragmatismo norteamericano y europeo; filosofía española e iberoamericana; historia de la filosofía. Algunas publicaciones recientes: «Sobre la interpretación del concepto orteguiano de "vocación"», Revista de estudios orteguianos, $\mathrm{n}^{\circ} 31,2015$, pp. 115-139; «Dimensiones del cuerpo y conocimiento moral en Ortega y Gasset», en Azafea. Revista de filosofía, Vol. 18 (2016), en prensa; «Ortega y Kuhn: filosofías paralelas en base a sus fuentes», en Thémata. Revista de filosofía, $\mathrm{n}^{\circ}$ 54, diciembre de 2016, en prensa; «México en la mirada anglosajona: buscando al Humboldt integral», en Res publica. Revista de Historia de las Ideas Políticas, vol. 19, número 1 (2016), pp. $243-250$. 
de la vida ha cambiado mucho más que sus contenidos: hoy es inminencia, improvisación, acritud, prisa y aspereza» ${ }^{1}$. En tercer lugar, y quizá más interesante para nuestros actuales intereses, esta concepción ética nace desde una crítica a la situación política de su momento histórico. En este sentido, podemos leer en La rebelión de las masas que el Poder público, el Gobierno, «vive al día [...] vive sin programa de vida, sin proyecto. No sabe dónde va porque, en rigor, no va, no tiene camino prefijado, trayectoria anticipada $»^{2}$. Son esta clase de problemas los que creemos que trata de combatir con las nociones de vocación, proyecto, etc., y nos resulta notorio que, hasta hoy, sólo se haya atendido a la crítica del utilitarismo y la ética deontológica como origen de la ética orteguiana.

Por otra parte, si una idea de Ortega se ha repetido mecánicamente -aun con la imprecisión que supone siempre convertir algo en tópico- es su distinción entre los hombres egregios y los hombres-masa. No es objetivo de esta investigación criticar o aceptar tal diferenciación (en cualquier caso, generalmente mal entendida: pocas veces se menciona que la toma del poder por parte de los hombres-masa se debe, inicialmente, a la deserción de las minorías; cf. España invertebrada); lo que sí queremos señalar es que tal idea se encuentra en la base de toda la ética orteguiana, igual que era una idea socio-política la que le da origen. Señala Villacañas que «La época del pensamiento de Ortega que surge a finales de los años 20, orientada hacia la configuración de la razón vital, está marcada por el concepto trascendental de hombre masa [...]», siendo tal concepto «la condición estructural del pensamiento de Ortega en esta época» ${ }^{3}$. Nos parece que acierta. En la misma línea, señala el propio Villacañas en otro lugar que le parece «grave, muy grave teóricamente, que se proyecte sobre la sociedad -una estructura horizontal- la dimensión vertical y exclusivamente política de la relación mando-obediencia, mejores y peores, minorías egregias y masas» ${ }^{4}$; a propósito de ello nosotros ampliamos aún más la cuestión, considerando que esa división vertical se traslada no sólo a la sociología sino, vinculada con ésta, a la ética. Esto llevará a Cerezo a hablar de una ética aristocrática ${ }^{5}$.

Resultará esencial para nuestra investigación comprender que Ortega vincula la autenticidad a los hombres egregios y, sobre todo, la inautenticidad a las vidas vulgares, a los

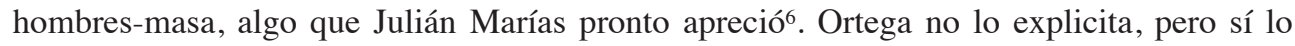
apunta de manera ostensible al titular un capítulo de La rebelión de las masas "Vida noble y vida vulgar, o esfuerzo e inercia"; o al sostener ideas como que «El hombre-masa es el hombre cuya vida carece de proyecto y va a la deriva» ${ }^{7}$.

1 Ortega y Gasset, J., Obras completas, Madrid, Taurus-Fundación José Ortega y Gasset, 2004-2010 (10 vol.), tomo IV, p. 257. En adelante, citamos las obras de Ortega como $O C$, seguido del tomo en romanos y la página en arábigos.

$2 O C, \mathrm{IV}, 401$.

3 Villacañas Berlanga, J. L., «Hacia la definición de un nuevo liberalismo. El pensamiento tardío de Ortega y Gasset», Arbor. Ciencia, pensamiento y cultura, vol. 187-750 julio-agosto (2011), p. 742.

4 Villacañas Berlanga, J. L., «Otros principios. Acerca de «España invertebrada», de José Ortega y Gasset», Archipiélago. Cuadernos de crítica de la cultura, $\mathrm{n}^{\circ}$ 58, 2003, p. 96.

5 Cerezo Galán, P., José Ortega y Gasset y la razón práctica, Madrid, Biblioteca Nueva y Fundación Ortega y Gasset-Gregorio Marañón, 2011, p. 227.

6 Marías, J., Acerca de Ortega, Madrid, Espasa Calpe, 1991, p. 177.

$7 O C, \mathrm{IV}, 402$. 
No obstante lo anterior, es pertinente admitir que otros autores han visto la cuestión de modo inverso, es decir, entendiendo que es la ética de Ortega la que determina su visión política $^{8}$; nos parece que tal postura es inverosímil, pero es deber intelectual dejar anotadas las posturas opuestas a las propias.

\section{Retórica orteguiana y supuestos misteriosos}

Uno de los supuestos generales del opúsculo de Aranguren La ética de Ortega es que Ortega suele recurrir a la exageración retórica. Siendo cierto que es deliberadamente exagerado en algunas cuestiones, a fin de hacerlas más claras, no podemos aceptar que todo lo que dice Ortega sea fruto de la exageración; y, en esa medida, no estamos de acuerdo con Aranguren. Sin embargo, hay una apreciación sobre la retórica orteguiana que, aunque se ha mencionado en múltiples ocasiones, rara vez se ha puesto en relación con el tema que ahora nos ocupa.

Como intentaremos demostrar en las páginas siguientes, la ética orteguiana de la vocación supone una grave cantidad de problemas, algunos de gran profundidad. Sin embargo, es indudable que, cuando se leen por primera vez algunos de sus textos, éstos resultan gratificantes y atractivos. Esto se debe, en primer lugar, al estilo impecable del autor; pero, en segunda instancia, apreciamos que una idea procedente de Meditaciones del Quijote, y fundamental en todo este entramado ético, es la que nos hace dar un paso, quizá, injustificado: la posibilidad de ser héroes. Así, dirá que «todos llevamos dentro como el muñón de un héroe» ${ }^{10}$. La posibilidad nos suena estupenda; sin embargo, justamente ahí reside la trampa de la retórica orteguiana, ya que el héroe no es aquí el personaje afamado que alcanza una gloria mundana. De ese héroe sólo se conserva el esfuerzo: «Héroe es [...] quien quiere ser él mismo» ${ }^{11}$, lo cual no deja de suponer lo que Ortega busca desde la primera página de su primer libro: la «plenitud» que hay en cada cosa y que se ha de buscar amorosamente ${ }^{12}$.

Visto de esta manera, observamos que Ortega nos da la posibilidad de ser héroes; pero de éstos sólo mantenemos la lucha esforzada, no el premio. Dicho en términos que el autor maneja, es estupendo soñar con ser un héroe, pero éste se aleja de «el héroe que la historia ensalza, el personaje romántico que la novela idealiza» ${ }^{13}$. A ello nos referíamos con la alusión a la retórica orteguiana.

Hay otros aspectos que nos parecen que, brillantes en lo retórico, son difíciles de sostener en el plano teórico, y que suponen la base del edificio ético orteguiano. De entre ellos, quizá el más problemático es el concepto de fondo insobornable. Este fondo insobornable viene definido con particular "claridad" en Ideas sobre Pío Baroja:

8 Cf. Díaz Álvarez, J. M., «Cuestión de libertad. Ética y filosofía política», en J. Zamora Bonilla (ed.), Guía Comares de Ortega y Gasset, Granada, Comares, 2013, p. 266.

9 Madrid, Taurus, 1966 ( $3^{\mathrm{a}}$ ed.).

$10 O C, \mathrm{I}, 820$.

$11 O C, \mathrm{I}, 818$.

$12 O C, \mathrm{I}, 747$.

13 OC, II, 216. 
...ese núcleo último e individualísimo de la personalidad [que] está soterrado bajo el cúmulo de juicios y maneras sentimentales que de fuera cayeron sobre nosotros. Sólo algunos hombres dotados de una peculiar energía consiguen vislumbrar en ciertos instantes las actitudes de eso que Bergson llamaría el yo profundo. De cuando en cuando llega a la superficie de la conciencia su voz recóndita14.

Esta idea es, probablemente, de las más antiguas en el pensamiento de Ortega ${ }^{15}$, tornándose fundamental no sólo en su obra, sino en su vida. Sin embargo, no podemos dejar de advertir que de este fondo insobornable, que en último término es el sí mismo de cada cual de que brotan sus naturales inclinaciones -determinando, pues, su vocación en buena medida: será lo que genere qué "nos llama" la atención (y «nada nos define tanto como cuál sea nuestro régimen atencional») ${ }^{16}$ y en última instancia, la base de nuestro efectivo vivir, ya que «...vivir es una operación que se hace desde dentro hacia afuera, y es un brotar o manar continuo desde el secreto fondo individual hacia la redondez del mundo» ${ }^{17}$ - de ese fondo insobornable, decimos, no se aclara nada más. Tampoco los estudiosos han conseguido dar más que algunas aproximaciones que emparentan a Ortega, por ejemplo, con San Agustín y su meditación en torno a la esfera de lo íntimo, o recurriendo a ideas como que «el yo mismo se realiza justamente en lo que soy en el fondo» ${ }^{18}$, siendo lo segundo el fondo insobornable y lo primero el yo, digámoslo así, "empírico". En suma, Ortega maneja una intuición que sólo puede intentar "hacérnosla ver". Tal cosa, perfectamente válida en otros campos del saber, nos parece que juega aquí el papel de un falso axioma: no se puede justificar (como axioma que es), pero no resulta en modo alguno evidente. Esto permite a Mariano Rodríguez afirmar, y lo compartimos, que «la reflexión orteguiana da entrada al misterio, algo que la filosofía llamada analítica tratará siempre de evitar» ${ }^{19}$. Y es que el propio Ortega condena tal actitud: «Querer aclarar el hecho indubitable por una suposición, por un hecho, cuando menos dudoso, es un absurdo» ${ }^{20}$.

Esta problematización del fondo insobornable supone una primera estocada a la ética de la vocación, pues su operatividad en el pensamiento de Ortega es, insistimos, fundamental: en nosotros habría «un fondo insobornable que no se deja desorientar nunca por completo. Es a este fondo al que debemos seguir en la toma de decisiones. Es buceando en lo más íntimo de nosotros cuando encontramos las verdaderas respuestas y el camino adecuado a seguir» ${ }^{21}$. Esto guiará las páginas siguientes, en las que, implícitamente, estaremos mane-

$14 O C$, II, 225.

15 Cf. Ortega y Gasset, J., Cartas de un joven español, Madrid, Ediciones El Arquero, 1991; particularmente las cartas a su padre (pp. 85-294) y a su novia (pp. 295-575).

$16 O C, \mathrm{~V}, 479$.

$17 O C$, II, 742.

18 Parente, L., «El fondo insobornable en la descripción barojiana y en la reflexión orteguiana», en A. Regalado y J. Lasaga (eds.), Lecturas y diálogos en torno a Pío Baroja, Madrid, CSIC-Los libros de la catarata, 2011, p. 207.

19 Rodríguez González, M., «La cuestión del yo en Ortega», en A. Domínguez, J. Muñoz y J. De Salas (coord.), El primado de la vida. (Cultura, estética y política en Ortega y Gasset), Cuenca, Universidad de Castilla-La Mancha, 1997, p. 21.

20 OC, II, 516.

21 Campillo Ortega, J. M., «El concepto de vocación en Ortega», en José González-Sandoval Buedo, Ortega y la filosofía española, Murcia, Sociedad de Filosofía de la Región de Murcia - Biblioteca Saavedra Fajardo de Pensamiento Político Hispánico, 2004, p. 48. 
jando una hipótesis que se desprende de este carácter de suposición del fondo insobornable: que también la vocación es un supuesto difícilmente sostenible y que, no obstante, supondrá trabas para cierta concepción de la libertad.

\section{El cumplimiento de la vocación}

\subsection{Aspecto epistemológico}

Para Ortega, es la circunstancia, elemento crucial de su filosofía, la que nos va indicando cuál es nuestra vocación, esto es, el yo que tenemos que llegar a ser ${ }^{22}$. Sin embargo, deja algo en el aire: ¿cómo puedo saber si estoy cumpliendo mi vocación? No disponemos de espacio para ofrecer verdaderas respuestas; es probable que no las haya. Sin embargo, es preciso dejar planteadas ciertas dificultades que encontramos, pues tal es, justamente, el objetivo de este trabajo.

La cuestión es más problemática de lo que parece, ya que, a decir verdad, no sabemos si estamos cumpliendo nuestra vocación. «La revelación [de nuestra vocación] se produce, si se produce, como respuesta, inserta en el curso de la actuación vital) [...] La vocación sólo es conocida -habría que decir "sospechada"- después de ser actuada», afirma Lasaga ${ }^{23}$. Esto es rigurosamente cierto; sin embargo, supone un problema evidente: está muy bien saber -si llegamos a saberlo- que en un momento dado hemos cumplido con lo que debíamos ser; sin embargo, la vida es, según Ortega, hacia delante: en cada momento presente no tenemos realmente una indicación de lo que debemos hacer para ser auténticos, quedando como única posibilidad el método de ensayo y error (válido en ciencia, peligroso en la vida): el sí mismo «sólo se aclara a posteriori, en el choque con lo que le va pasando» ${ }^{24}$. Dirá Ortega que, ordinariamente, no tenemos sino un «vago conocimiento» de él ${ }^{25}$. Quizá habría que meditar detenidamente si esto entra en el ámbito de la filosofía: según comenta López Molina, creemos que no sería el caso ${ }^{26}$. También sería interesante explorar la posibilidad de estudiar si la vocación y el conocimiento de la misma se mueven en el ámbito de lo que Sergio Rábade llama formas impropias de racionalidad, o quizá formas intermedias ${ }^{27}$-ya que hablamos de una forma deficiente de conocimiento «tan difícil de vencer que, en algunos casos, las acabamos asimilando a lo irracional o incognoscible, sin que sean efectivamente tales $»^{28}$.

La dificultad no acaba ahí. Señala Ortega como autenticidad llegar a ser el que verdaderamente se es, alcanzar la perfección de uno mismo. Más abajo veremos cuán problemático es este punto respecto a la libertad; por ahora, nos conformamos con plantear una dificultad: ¿quién y cómo determina cuál es mi estado de máxima perfección, al cual debo aspirar?

22 Cf., por ejemplo, $O C, \mathrm{~V}, 86$.

23 Lasaga Medina, J., Figuras de la vida buena, Madrid, Enigma Editores, 2006, p. 205.

$24 O C, \mathrm{~V}, 130-131$.

$25 O C, \mathrm{~V}, 124$.

26 López Molina, A. M., «La experiencia filosófica en Ortega y Gasset», Anales del seminario de metafísica, XVIII, 1983, p. 25.

27 Cf. Rábade Romeo, S., Obras, Vol. IV, Madrid, Trotta - CEU Don Bosco, 2009, pp. 268-273.

28 Ibídem, p. 266. 
En tercer lugar, a propósito del aspecto epistemológico de la vocación, esto es, cómo puedo conocerla y saber si la estoy cumpliendo, podemos plantearnos si no hay en Ortega un cierto intelectualismo moral, esto es, la máxima platónica de que el que obra mal lo hace por ignorancia. En este punto debemos ser coherentes con lo que venimos defendiendo: no hablamos de mal moral sino de mal respecto a la autenticidad; dicho de otra manera, pudiera pensarse que, en opinión de Ortega, se puede (y suele) obrar mal/inauténticamente por no conocer uno su vocación; y esto ocurre cuando no se reabsorbe la circunstancia ${ }^{29}$. Sin embargo, habida cuenta de la dificultad de conocer la vocación, tal afirmación nos parecería pedir demasiado de nosotros mismos.

Ahora bien, al margen de ese criterio enigmático de diálogo con la circunstancia (enigmático en tanto que, por más que Ortega lo intente hacer ver como evidente, no está tan claro cómo se reabsorbe ésta), sí que nos ofrece el autor no uno, sino dos criterios para saber si alguien cumple con su vocación. Uno de ellos sólo puede realizarse en tercera persona (y $a$ posteriori): realizar una biografía, tal y como Ortega la entiende, nos permite determinar si alguien cumplió con el personaje ideal que tendría que haber encarnado. Carecemos de espacio para justificar nuestra objeción a este punto, la cual, no obstante, se apoya en una idea: realizar una biografía del modo que Ortega propone es, sencillamente, imposible. Así, por mucho que el genial filósofo pretenda ver desde dentro la vida ajena, punto de partida de toda biografía, resulta extremadamente difícil comprender cómo debía haber sido la vida de Goethe sin Weimar, o de Velázquez fuera de la Corte Real, más allá de hipótesis que excluyeran cosas como el azar. Tiene razón Jaime de Salas cuando afirma que «La reconstrucción de una perspectiva [y, en último término, tal cosa es una biografía] es siempre hipotética y falible» ${ }^{30}$. Lamentamos no poder dar aquí precisiones sobre nuestra postura, al ser el espacio limitado y el tema tangencial al nuestro; sin embargo, habrá de ser estudiado con un mayor detenimiento en otra ocasión.

El segundo criterio que Ortega nos ofrece para saber si estamos cumpliendo con nuestra vocación no funciona a posteriori, sino en pleno acto: el placer y el dolor, caracterizados a veces como gusto y disgusto. Así habla en Pidiendo un Goethe desde dentro: «El hombre no reconoce su yo, su vocación singularísima, sino por el gusto o el disgusto que en cada situación siente. La infelicidad le va avisando, como la aguja de un aparato registrador, cuándo su vida efectiva realiza su programa vital, su entelequia, y cuándo se desvía de ella» ${ }^{31}$. Esta es la única manera de que dispone cada uno para saber si cumple con el mandato de encaminarse a ser el que tiene que ser. Sin embargo, Jaime de Salas aporta el escollo clave al respecto: «No es un criterio muy seguro en la medida en que se mezcla aspectos temperamentales con decisiones éticas. Además uno puede caer en el mal humor por muchas otras razones como el propio Ortega reconoce cuando pone de manifiesto las dificultades que la circunstancia pone a la realización de la vocación» ${ }^{32}$; Marías, más tenue, sólo impugnaría este criterio si el mal humor «no se justifica muy especialmente por condiciones exteriores o acontecimientos muy precisos» $»^{33}$.

29 Sobre la reabsorción de la circunstancia, cf. $O C$, I, 756.

30 De Salas, J., «Perspectiva y el método de salvación en Ortega», en Javier Zamora Bonilla (ed.), Guía Comares..., op. cit., p. 234.

$31 O C, \mathrm{~V}, 130$.

32 De Salas, J., «Perspectiva y el método...», op. cit., pp.241-242.

33 Marías, J., Acerca de Ortega, op. cit., p. 190. 
Debemos observar que José Lasaga se muestra crítico con nuestra interpretación:

\begin{abstract}
¿Resulta entonces que la autenticidad, núcleo de la vida moral se fía a un sentimiento? No. En realidad significa que hemos de aceptar el hecho de que la autenticidad, en cuanto que no es sino otro sinónimo de la bondad moral, sólo parece estar en la medida en que no la "sintamos"; y si la "sentimos", como el fariseo de los Evangelios, es que la hemos perdido ${ }^{34}$.
\end{abstract}

Sin embargo, no podemos estar de acuerdo con él por dos motivos. En primer lugar, porque explícitamente Ortega afirma lo que él niega, como hemos visto. En segundo lugar, porque este pasaje equipara autenticidad con bondad moral, algo totalmente erróneo como se desprende, por ejemplo, de Mirabeau o el político. Sospechamos que la debilidad fundamental de Lasaga radica en que no llega realmente a problematizar el pensamiento de Ortega.

Justamente este punto es decisivo para las investigaciones que han de seguir a la presente. Así, creemos ver en este aspecto, que toma como criterios de acción el placer y el dolor (no de manera hedonista) un elemento clave para empezar a tejer una conexión aún no bien explorada entre la obra de Ortega y Gasset y el pensamiento pragmatista norteamericano de finales del siglo XIX y principios del $\mathrm{XX}^{35}$.

En definitiva, este epígrafe se resume en pocas palabras: nunca podemos estar seguros ni de cuál es nuestra vocación ni de si estamos cumpliéndola. Cada vez parece más complicado llegar a ser el que tenemos que ser. Tal es nuestra tesis.

\title{
3.2. Aspecto práctico
}

Hemos visto ya que es muy difícil, si no imposible, conocer nuestra vocación y saber si la estamos cumpliendo. Variemos ahora ligeramente el modo de preguntar para plantear una nueva dificultad: ¿es posible cumplir nuestra vocación? En principio, Ortega nos contestaría con un rotundo sí, aunque nos llevaría mucho esfuerzo, como muestra, entre otros, José Eduardo Martínez Fernández ${ }^{36}$. Atendiendo exclusivamente al pensamiento orteguiano, tal y como nos hemos propuesto, la respuesta es inapelable: aunque no conozcamos nuestra vocación y no sepamos si la estamos cumpliendo, es posible que, de hecho, estemos siendo el que tenemos que ser, ya que no hay una imposibilidad metafísica. Desde luego que, a tenor de lo que venimos indicando en estas páginas, tal cosa nos parece muy difícil; pero no por ello es imposible. Sin embargo, la cosa cambia si nos atenemos al común de las vidas reales. A lo que estamos apuntando es a la posibilidad de la reversibilidad y la redención de la vida a partir del tema de la vocación.

34 Lasaga Medina, J., Figuras..., op. cit., p. 233, n. 11.

35 Como muestra de la presencia de este criterio en el pragmatismo, cf., por ejemplo, Dewey, J., La miseria de la epistemología, Madrid, Biblioteca Nueva, 2000, caps. IV y V.

36 Martínez Fernández, J. E., «Ortega y Gasset: hacia una nueva concepción de una ética radicada en la vida», en Actas “Conversaciones sobre Ortega” (I Jornadas Culturales), I. N. B. Príncipe de Asturias, Aller, 1983, p. 180 . 
Ortega se refiere a la trayectoria ideal de nosotros mismos, al personaje que tenemos que ser, como «una línea o perfil individualísimo de existencia ${ }^{37}$. Claro es que esa idea de la "línea" es metafórica; pero nosotros vamos a utilizarla, también metafóricamente, para mostrar una dificultad del pensamiento del filósofo.

El problema podemos plantearlo de la siguiente manera. A lo largo de una vida, la toma ininterrumpida de decisiones puede arrojar dos posibilidades: que siempre atinemos con la que corresponde al cumplimiento de nuestra vocación; o que, en algún momento (o en todos), tomemos una decisión que no es adecuada. Dada la dificultad de conocer nuestra vocación, parece lógico pensar que el segundo caso debe ser el habitual en las vidas humanas. Pues bien, nuestra pregunta es la siguiente: ¿puede alguien que haya "fallado" en una o varias ocasiones recuperar la senda que la vocación sugiere? El problema tiene más consecuencias de lo que parece, ya que, si no es posible enmendar las decisiones que no llevan a la vida auténtica, en la práctica todos estamos condenados a llevar una vida inauténtica; si es posible enmendar la equivocación, en cambio, estamos dando toda la importancia a la finalidad y quitándosela a los medios, por lo que, más que vivir nuestra vida (que es justamente el flujo constante de decisiones, no la llegada a puerto), estaríamos viviendo la de otro o la de nadie, como ocurre en el caso del caprichoso o el frívolo ${ }^{38}$.

Ortega parece aceptar que cabe corregir el rumbo. Así, en Azorín o primores de lo vulgar, señala: «Yo creo que todo hombre superior ha tenido esta facultad de asistir a su propia existencia, de vivir un poco inclinado sobre su propia vida, en actitud a la vez de espectador exigente y de investigador alerta, pronto a corregir una desviación o desperfecto, presto al aplauso y al silbido» ${ }^{39}$. Ese aplauso y ese silbido son el ánimo para seguir la misma línea (nunca mejor dicho: línea) o la advertencia de que hay que modificar el plan, respectivamente. Sin embargo, tal postura no parece encajar del todo con la seriedad y el ansia orteguianas por mostrar que en la vida hay que tomar las decisiones de manera reflexiva, no valiendo echarse atrás. El tema es, en cualquier caso, problemático.

\subsubsection{Una posible reinterpretación desde María Zambrano}

Aunque este trabajo busca más problematizar que dar soluciones, creemos que una reinterpretación de lo que aquí se propone puede salvar el problema. Ortega parece pensar la trayectoria ideal como una línea que debemos ir siguiendo hasta llegar a nuestro destino. Ante la dificultad que aquí planteamos, sugerimos una posible alternativa que arranca de un texto de María Zambrano. Reflexionando sobre San Agustín en La agonía de Europa, aprecia la autora que el yo soñado sólo puede alcanzarse en distintos momentos dispersos; $\mathrm{y}$, de hecho, hacerlo es «la mayor necesidad de todas las biológicas y psicológicas» ${ }^{40}$. Los supuestos antropológicos de la filósofa malagueña y los de Ortega son notoriamente diferentes; sin embargo, esta idea puede servirnos para reinterpretar la noción de trayectoria ideal en el caso del madrileño. Así, creemos que la objeción que planteamos podría salvarse si no entendemos la trayectoria como una línea continua, sino discontinua. Cada

$37 O C, \mathrm{~V}, 299$.

38 Cf. $O C, \mathrm{~V}, 86$.

39 OC, II, 295.

40 Zambrano, M., La agonía de Europa, Madrid, Mondadori, 1988, p. 56. 
punto ocuparía el lugar de un momento crucial de nuestra vida en el cual no podemos fallar: hablamos de las grandes decisiones vitales. De esta manera, el ser humano no quedaría totalmente constreñido a una trayectoria vital pre-fijada y difícil de cumplir: su autenticidad vendría determinada por las decisiones tomadas en momentos concretos (más o menos numerosos), aunque habría que dilucidar - de manera problemática, cierto es- un límite negativo para el resto de ocasiones; es decir, habría que postular el umbral que en ningún momento, crucial o no, debería sobrepasarse si uno quiere ser uno mismo. Dicho aún de otro modo, el riesgo mayor desde esta reinterpretación no sería no llegar a ser el que se tiene que ser, pero aún no se es, sino dejar de ser el que se es mientras se va acertando en la toma de decisiones fundamentales.

Esta idea toma pie también en una afirmación de Aranguren: «Hay instantes en los que, fugazmente, se diría que va a producirse ese "prodigioso fenómeno" de la coincidencia entre nuestra vida proyectada y nuestra vida real, que es en lo que consiste la felicidad. Pero no se produce ${ }^{41}$. Nuestra idea es, justamente, que la vocación podría entenderse como el acierto en esos instantes, y sólo en esos instantes -insistimos, siempre que no se sobrepase un límite negativo.

Rogamos al lector que no entienda este pequeño apartado como una toma rotunda de posición; simplemente tratamos de abrir nuevas vías de investigación a propósito del particular que nos ocupa, abiertas plenamente a la crítica.

\section{La vocación y los límites de la libertad}

\subsection{La circunstancia como pie forzado}

Dijimos arriba que es la circunstancia la que, como un pie forzado, nos muestra lo que hay que hacer ${ }^{42}$; y, haciendo lo que hay que hacer, diría Ortega, llegamos a lo que tenemos que ser. Ha llegado el momento de problematizar este punto. Ya hemos ido viendo aquí y allá que lo que tenemos que ser, por más que Ortega insista, no es algo que nos resulte tan evidente desde la contemplación perspectivada de la circunstancia. Más aún: ni siquiera las opciones entre las que podemos elegir -y entre las cuales estaría la adecuada- nos resultan claras, como muy bien lo apunta Rábade ${ }^{43}$.

No es el anterior, sin embargo, el mayor problema a que las tesis orteguianas se enfrentan. Para entender lo que queremos mostrar es preciso apreciar debidamente algo que, aunque notorio, no suele destacarse: la generación a la que pertenecemos es, también, parte de nuestra circunstancia. Lo que con ello estamos sugiriendo es que, igual que en cada generación los individuos tienen su particular modo de afrontar las cosas (en los términos referidos a nuestro asunto diríamos que cada sujeto tiene $s u$ vocación), es obvio que cada individuo reacciona a determinadas situaciones de la manera típica en su generación. Jaime de Salas sí ha advertido este punto al hablar de una necesidad contingente:

41 Aranguren, J. L., La ética de Ortega, op. cit., pp. 74-75.

42 Cf. $O C, \mathrm{~V}, 86-87$.

43 Cf. Rábade Romeo, S., Obras, vol. IV, op. cit., p. 600. 
Podríamos haber nacido en otro lugar y tener otra familia, haber ido a otra escuela o colegio, haber encontrado otras personas durante la adolescencia, etc. Pero una vez pasado eso y aun sabiendo que el hombre tiene siempre una capacidad de interpretar e incluso de enmendar su pasado, también es cierto que los términos del relato personal están fijados y parte de la obligación ética consiste en reconocerlo ${ }^{44}$.

La interpretación del profesor De Salas es perfecta respecto al pensamiento orteguiano. Sin embargo, se desprende de todo ello una consecuencia que ha pasado inadvertida. El que nace en las coordenadas espacio-temporales $x, y, z, t$ estará "forzado" a tener tal vocación -aunque esto implica que o bien a) no se tiene en cuenta el carácter, la personalidad, en suma, la situación ${ }^{45}$ del sujeto o b) dicho carácter, personalidad, situación vienen dados por el entorno. Sin embargo, las coordenadas del nacimiento no las elegimos nosotros, por lo que o 1) somos víctimas de la libertad y albedrío de Dios o 2) somos hijos del azar. En cualquier caso, se nos amputa la libertad no de hacer, sino de elegir quién tenemos que ser. Más abajo abordaremos este problema respecto a la libertad que ya aquí se está apuntando.

No es el único problema que la ética de la vocación nos supone en relación con la circunstancia. No cabe duda de que Ortega, en el plano sociológico, aboga por dar más peso a la subjetividad que a la sociedad a la hora de determinar la toma de decisiones (en la línea de autores como Weber y decididamente en contra del positivismo de Durkheim, entre otros). La prueba más patente de ello es, precisamente, su ética de la vocación. Sin embargo, al menos en cierta medida, dicha ética, en relación con su concepción de la circunstancia, supone un ataque a la subjetividad. Para ilustrar a qué nos estamos refiriendo, acudamos a El tema de nuestro tiempo:

... el pueblo romano es un cierto repertorio de tendencias tales que se van desenvolviendo en el tiempo, paso a paso. En cada estadio de este desarrollo se halla preformado el subsecuente [...] Es, en efecto, un azar que en el siglo I antes de Jesucristo viviese un hombre con el genio singular de César. Pero lo que César hizo brillantemente con su genio singular lo hubieran hecho sin tanta brillantez ni plenitud otros diez o doce hombres, cuyos nombres conocemos ${ }^{46}$.

Un trabajo que tratase de sólo elogiar el pensamiento orteguiano, mostrando su coherencia, señalaría que en la cita se alude a la peculiaridad, en la especie de brillantez genial, de Julio César. Acertaría. Pero no podemos dejar de mostrar, o al menos advertir, que cabe una segunda lectura de la cita: la que considera que lo que hizo César, mejor o peor, pudieron hacerlo otros. Esto, que pudiera parecer baladí, no lo es en modo alguno, ni en el plano teórico ni el práctico. Respecto al primero, supone una de las tesis fuertes de este trabajo: en el ámbito de la ética, la circunstancia fagocita al yo, al individuo, rompiendo el equilibrio entre el yo y la circunstancia que la mágica expresión orteguiana señala. Esto se

44 De Salas, J., «Ortega y la ética de la perspectiva», Revista de Estudios Orteguianos, Madrid, nº 6, 2003 , p. 100.

45 Sobre la situación en el sentido en que aquí la entendemos: Rodríguez Huéscar, A., La innovación metafísica de Ortega. Crítica y superación del idealismo, Madrid, Biblioteca Nueva, 2002, pp. 162-170; y Éthos y lógos, Madrid, UNED, 1996, passim.

46 OC, III, 568. 
entiende en la medida en que la circunstancia reclama que alguien haga algo; y parece que, aun estando unos sujetos (César, Mirabeau) mejor dotados que otros para ello, importa más qué se haga que quién lo haga. En el plano práctico se aprecia mejor la gravedad del asunto. Querido lector: cambie usted el nombre de César por el suyo. Lea que lo que usted hace, tan trascendente como sea, lo haría otro en su lugar si usted no estuviera; sólo cambiarían las formas, los matices de su peculiar manera de hacer las cosas, pero no el fondo ${ }^{47} \cdot ¿^{\mathrm{No}}$ resulta difícil de aceptar?

\subsubsection{Circunstancia y educación}

Queda claramente un punto por aclarar respecto a nuestra postura: ¿cómo puede adentrarse la circunstancia en mi yo personal hasta el punto de determinar mi vocación? Nuestra tesis es que la cuestión radica en la educación. No podemos detenernos tanto como es debido en este punto; sin embargo, sí podemos dejar claramente sentados algunos aspectos esenciales. Para ello hay que adherir, a lo que ahora vamos a exponer, todo lo que venimos indicando, pues el presente epígrafe culmina buena parte de la investigación; aunque, a su vez, es el pie para tratar la cuestión de la libertad.

Que la circunstancia se adentre en el sujeto no es sólo el objetivo preciso de éste (reabsorberla); también es algo que ocurre, a nuestro entender, de forma "subrepticia" (si es que cabe imputar intencionalidad a la circunstancia) según se desprende del pensar de Ortega -quien, por su parte, difícilmente aceptaría todo esto. Citamos nuevamente a Salas: «una misma cultura se modula de formas diferentes en cada persona de acuerdo con avatares del proceso de aprendizaje, y las diferencias temperamentales» ${ }^{48}$. Esto ha de determinar, pues, la perspectiva del individuo; pero también su vocación. Insistimos: la clave será la educación.

El propio Ortega, en La pedagogía social como programa político, apunta al asunto:

El niño es un detalle de la familia: en su menudo corazón se hallan condensadas las esencias de las domésticas tradiciones; su memoria, aunque breve, es una tela sutil urdida con los hilos de las impresiones familiares; su totalidad espiritual es un producto del sistema de ideas, aspiraciones y sentimientos, que reina en el hogar paterno $^{49}$.

Ahora bien, hemos indicado, al hablar Jaime de Salas de las necesidades contingentes, que la familia es parte de la circunstancia. Por ello podemos afirmar que la circunstancia va a determinar en el niño ideas, aspiraciones, sentimientos, etc.

Antes de continuar, debemos notar que no sólo la familia será clave para la determinación de la vocación por parte de la circunstancia. También la ya mencionada generación tendrá mucho que decir, pues será esencial para que tendamos hacia unos u otros valores (habida cuenta de que éstos son los orientadores de nuestras elecciones) ${ }^{50}$. Así lo señala Lasaga: «Los valores como entes ideales son eternos, como la línea recta y el ángulo agudo, pero

47 Cf. Campillo Ortega, J. M., «El concepto de vocación en Ortega», op. cit., p. 47.

48 De Salas, J., «Ortega y la ética de la perspectiva», op. cit., p. 90.

49 OC, II, 95.

50 Cf. $O C$, II, 278 y 550. 
su coeficiente de preferibilidad cambia con las generaciones, a las que caracteriza, precisamente, un régimen distinto de sensibilidad para los valores» ${ }^{51}$. Pero podemos ir aún más allá, leyendo a un Rodríguez Huéscar que se pronuncia en la misma línea que nosotros de manera absolutamente actual:

En la actualidad, los ensayos de intervención progresiva en la intimidad de las personas y de manipulación de las conciencias en las sociedades masificadas, politizadas y tecnificadas, amenazan con llegar - ¿no están llegando ya?- a formas de apropiación y de planificación de la conducta colectiva que penetra en capas cada vez más profundas de la personalidad, y que, en la misma medida de esa penetración, destruyen aquélla, aproximando cada vez más al individuo medio de esas sociedades (al hombre-masa de Ortega) a la triste condición de un robot viviente ${ }^{52}$.

Quizá la mejor manera de expresar nuestra posición se encuentra, no obstante, en un texto de Mariano Rodríguez González: «...el yo deberá ser pensado desde el hecho de que se construye, se cultiva, se educa. El yo comienza siendo material pedagógico, y cumple a la Pedagogía determinar los ideales que deberá realizar el yo, para en un segundo momento disponer los medios necesarios a tal realización $»^{53}$.

Aunque tal vez el gran ejemplo de esto, anterior a la aparición de Ortega, lo encontramos en un autor bien conocido por el filósofo: Miguel de Unamuno. Así, ¿qué hace Avito Carrascal, protagonista de Amor y pedagogía, sino intentar determinar la vocación de su hijo Apolodoro; y qué hace Marina, madre de éste, sino lo mismo, pero en dirección inversa?

\subsection{Destino y libertad}

En las páginas precedentes venimos apuntando, de manera dispersa, que en la ética de la vocación se está jugando, en buena medida, el problema de la libertad. El punto de partida al respecto es que la circunstancia es la que ofrece las distintas opciones vitales entre las que podemos optar. En este sentido, resulta evidente que no tenemos libertad absoluta para hacer lo que nos venga en gana. Así, ¿qué libertad es la que, según Ortega, tenemos cada uno de nosotros de cara a elegir nuestra vida? Podemos advertir que hay dos aspectos en que gozamos de libertad: somos libres para aceptar o no el camino que nos marca nuestra vocación (llevando o no una vida auténtica). En este sentido, no sólo gozamos de libertad, sino que somos necesariamente libres: que el hombre no sea algo ya, sino que sea perpetua tarea, implica que constantemente ha de elegir, y sólo se puede elegir cuando, habiendo múltiples posibilidades, no tenemos que optar obligatoriamente por una o por otra (aunque, debemos notarlo, para Ortega -quizá equivocado- sólo hay una opción acertada: la que supone cumplir nuestra vocación).

Hay un segundo sentido en que Ortega habla de libertad y que, por sobrentendido, rara vez se explicita. Si aceptamos nuestra vocación -aunque también ocurre si ponemos nuestra vida a otra cosa-, el camino hasta la plenitud es asunto nuestro. En este sentido, la circunstancia propone y nosotros disponemos; o, dicho de otro modo, tenemos libertad para elegir los medios hacia

51 Lasaga Medina, J., Figuras..., op. cit., p. 149.

52 Rodríguez Huéscar, A., La innovación metafísica de Ortega..., op. cit., p. 173.

53 Rodríguez González, M., «La cuestión del yo en Ortega», op. cit., pp. 16-17. 
nuestro objetivo vital, habida cuenta de que éstos pasaran a ser parte de nuestro pasado y, en esta medida, de nosotros mismos («el hombre no tiene naturaleza, sino que tiene... historia») ${ }^{54}$.

Así pues, hay en Ortega dos niveles de libertad, a saber: en sentido primario ontológicamente, esto es, libertad para aceptar o no la vocación; y en sentido secundario, que entendíamos como libertad para elegir los medios. Sobre la segunda, poco tenemos que decir; la primera, en cambio, nos parece sobremanera problemática.

Nos resulta inaceptable, en definitiva, que haya un verdadero yo que sea el que tenemos que ser, aunque podamos no llegar a serlo nunca. Lo interesante es que nos parece inaceptable dentro de la obra de Ortega; es decir, choca con algunas de las tesis más fundamentales, $\mathrm{y}$, en particular, con su noción de autenticidad. Y es que ser el que tengo que ser no es, tal y como hemos visto, sino lo que la circunstancia exige o necesita o pretende que seamos. Pero hemos indicado que la circunstancia incluye la generación, y la particular sensibilidad para ciertos valores que conlleva; la familia y la educación que se da en casa o en el entorno; etc.

Con todo, se está abriendo la puerta para una máxima heteronomía o, dicho en otros términos, para la dominación. A eso es exactamente a lo que apuntaba la última cita de Rodríguez Huéscar: nada tan fácil para un padre como inculcar a un hijo ciertos valores, ciertas creencias, logrando con ello dotar de un cierto perfil a la circunstancia del joven. Si atendemos a Vitalidad, alma, espíritu veremos que el niño, carente de centro, no tiene aún vocación ${ }^{55}$. Efectivamente, no la tiene por sí, le viene de fuera. Y aquí apuntamos que puede ser determinada por esa parte de la circunstancia que llamamos otros.

Retomando la querida metáfora aristotélica del arquero ${ }^{56}$, en nuestra mano está decidir si queremos dar al blanco de la diana o no (libertad primaria); cabe la posibilidad de que, aunque decidamos seguir nuestra vocación -si es que la conociésemos- el viento desvíe la flecha (intervención del azar); e incluso podemos elegir el color de nuestra flecha (libertad secundaria); pero lo que de ninguna manera nos es dado elegir es la distancia a que la diana está. Tal cosa es terrible en la medida en que mientras para algunos la diana está lejana (requiriéndose la magnanimidad), para otros está próxima; y para éstos últimos, aunque opten por una vida auténtica, la vida se moverá en valores bajos. La suposición de que la política subyace a la ética en la obra de Ortega adquiere aquí su gravedad y su confirmación.

Pero adoptemos un punto de vista teórico, pues también en él resulta insostenible la ética de la vocación, en la medida en que despoja de valor llevar una vida auténtica. La clave radica en la secularización que esta filosofía supone. Ortega ha conservado el esquema clásico de la libertad, que niega la libertad metafísica; pero ha suprimido la presencia de Dios para sustituirla, en buena medida, por la circunstancia. Esto tiene una clara consecuencia: si, en el mundo clásico, un individuo acepta su circunstancia, se afirma en ella y, en definitiva, lleva una vida plena al servicio de cumplir su vocación, gana el Cielo, aunque no alcance su meta terrena; si no, va al Infierno (suponiendo algo que Ortega quiere pensar pero no puede sostener: que sólo haya vocaciones benignas ${ }^{57}$ ). Pero, en el caso de nuestro autor, la divinidad nos ha

$54 O C, \mathrm{VI}, 73$.

55 Cf. OC, II, 582.

56 Ética a Nicómaco, I, 2.

57 Sobre el debate en torno a la posibilidad de que haya vocaciones perversas en el sentido orteguiano, puede consultarse: Gutiérrez Simón, R., «Sobre la interpretación del concepto orteguiano de "vocación”», Revista de estudios orteguianos, $\mathrm{n}^{\mathrm{o}} 31,2015$, pp. 115-139. 
abandonado: el premio por ser auténtico es... ser auténtico. El castigo por ser inauténtico es... ser inauténtico. Sin embargo, nos parece que la postura está claramente debilitada, al menos en la medida en que el inauténtico -léase, por ejemplo, el señorito satisfecho- no padece por su decisión. La elección entre un modo de vida y otro ha perdido, literalmente, trascendencia.

La clave de la cuestión, en definitiva, podemos pensarla desde un texto de Sergio Rábade: «...la antropología de Ortega es una antropología exigente, de enorme responsabilidad. El hombre, libre por fuerza, tiene que hacerse su ser como persona: se programa en libertad y se debe comprometer con el proyecto que hace de su ser. No puede delegar en nadie. Está condicionado, que no determinado, por las circunstancias. Asume su rectoría y se hace responsable de su ser. Somos lo que decidimos ser» ${ }^{58}$. Sí, pero no: somos lo que decidimos ser, en la medida en que podemos optar por ser lo que tenemos que ser; pero lo que tenemos que ser -aunque decidamos ser otra cosa- no lo decidimos (tal cosa es el destino, «fatalidad retrospectiva» que podemos no alcanzar - por azar o por elección-, pero que en modo alguno nos es dado elegir, y que influye en nosotros «como hilo conductor de nuestras inspiraciones») ${ }^{59}$. Dicho más claramente, puedo ser el que yo decida y no ser el que debería ser, lo que convierte mi decisión libre en causa de mi inautenticidad. Si ser inauténtico fuese igual a ser malo, estaría condenándose mi ejercicio de la libertad, lo que nos parece inaceptable; pero ya hemos indicado que, para Ortega, esa igualdad no se da. De este modo, ser inauténtico, o, en términos positivos, ser auténtico, se ha convertido en algo irrelevante para el hombre.

En Introducción a una estimativa. ¿Qué son los valores? encontramos justamente la posición secularizada por Ortega. En nota al pie, Ortega se remite a Malebranche ${ }^{60}$ y ahí apunta que, según éste, los hombres deberían estar orientados a la búsqueda de los valores jerárquicamente superiores, pues son hechos a imagen y semejanza de Dios; aunque tienen libertad para ir en pos de valores inferiores. Ortega intentó eliminar a la divinidad en su ética de la vocación; pero creemos que lo hizo de manera fallida. Queremos advertir, en cualquier caso, que la cita de Malebranche que ofrece Ortega está incompleta. La transcribimos aquí, colocando en cursiva lo que Ortega omite:

...no pudiendo querer Dios que las voluntades que ha creado amen más a un bien menor que a uno más grande, es decir, que amen más lo que es menos digno de ser amado que lo que es más digno de ello, Él no puede crear ninguna criatura sin volverla hacia Él mismo y sin ordenarle que lo ame más que a todas las cosas; aunque pueda crearlo libre y con el poder de apartarse de Él61.

Se aprecia nítidamente que Ortega ha querido mantener el esquema, pero suprimiendo la alusión a la divinidad. La secularización es clara; y más cuando se lee unas líneas más abajo, en el texto del propio Malebranche: «Sólo la capacidad de amar mal, o más bien de amar mucho lo que no debemos amar, depende de nosotros» ${ }^{62}$.

58 Rábade Romeo, S., Obras, op. cit., vol. IV, p. 651

$59 O C, \mathrm{X}, 226$.

$60 O C$, III, 541, n. 1.

61 Malebranche, N., Acerca de la investigación de la verdad, Salamanca, Sígueme, 2009, p. 369.

62 Ibídem. 


\section{Bibliografía}

Aranguren, J. L., La ética de Ortega, Madrid, Taurus, 1966 ( $3^{\mathrm{a}}$ ed.).

Campillo Ortega, J. M., «El concepto de vocación en Ortega», en José González-Sandoval Buedo, Ortega y la filosofía española, Murcia, Sociedad de Filosofía de la Región de Murcia - Biblioteca Saavedra Fajardo de Pensamiento Político Hispánico, 2004.

Cerezo Galán, P., José Ortega y Gasset y la razón práctica, Madrid, Biblioteca Nueva y Fundación Ortega y Gasset-Gregorio Marañón, 2011.

De Salas, J., «Ortega y la ética de la perspectiva», Revista de Estudios Orteguianos, Madrid, $\mathrm{n}^{\circ}$ 6, 2003.

De Salas, J., «Perspectiva y el método de salvación en Ortega», en Javier Zamora Bonilla (ed.), Guía Comares de Ortega y Gasset, Granada, Comares, 2013.

Dewey, J., La miseria de la epistemología, Madrid, Biblioteca Nueva, 2000.

Díaz Álvarez, J. M., «Cuestión de libertad. Ética y filosofía política», en J. Zamora Bonilla (ed.), Guía Comares de Ortega y Gasset, Granada, Comares, 2013.

Lasaga Medina, J., Figuras de la vida buena, Madrid, Enigma Editores, 2006.

López Molina, A. M., «La experiencia filosófica en Ortega y Gasset», Anales del seminario de metafísica, XVIII, 1983.

Malebranche, N., Acerca de la investigación de la verdad, Salamanca, Sígueme, 2009.

Marías, J., Acerca de Ortega, Madrid, Espasa Calpe, 1991.

Martínez Fernández, J. E., «Ortega y Gasset: hacia una nueva concepción de una ética radicada en la vida», en Actas "Conversaciones sobre Ortega" (I Jornadas Culturales), I. N. B. Príncipe de Asturias, Aller, 1983.

Ortega y Gasset, J., Cartas de un joven español, Madrid, Ediciones El Arquero, 1991.

Ortega y Gasset, J., Obras completas, Madrid, Taurus-Fundación José Ortega y Gasset, 2004-2010 (10 vols.).

Parente, L., «El fondo insobornable en la descripción barojiana y en la reflexión orteguiana», en A. Regalado y J. Lasaga (eds.), Lecturas y diálogos en torno a Pío Baroja, Madrid, CSIC-Los libros de la catarata, 2011.

Rábade Romeo, S., Obras, Vol. IV, Madrid, Trotta - CEU Don Bosco, 2009.

Rodríguez González, M., «La cuestión del yo en Ortega», en A. Domínguez, J. Muñoz y J. De Salas (coord.), El primado de la vida. (Cultura, estética y política en Ortega y Gasset), Cuenca, Universidad de Castilla-La Mancha, 1997.

Rodríguez Huéscar, A., Éthos y lógos, Madrid, UNED, 1996.

Rodríguez Huéscar, A., La innovación metafísica de Ortega. Crítica y superación del idealismo, Madrid, Biblioteca Nueva, 2002.

Villacañas Berlanga, J. L., «Otros principios. Acerca de «España invertebrada», de José Ortega y Gasset», Archipiélago. Cuadernos de crítica de la cultura, nº 58, 2003.

Villacañas Berlanga, J. L., «Hacia la definición de un nuevo liberalismo. El pensamiento tardío de Ortega y Gasset», Arbor. Ciencia, pensamiento y cultura, vol. 187-750 (2011).

Zambrano, M., La agonía de Europa, Madrid, Mondadori, 1988. 
